\title{
Pterospoda nigrescens (Hulst), a synonym of Ixala klotsi Sperry (Lepidoptera, Geometridae, Ennominae)
}

\author{
Clifford D. Ferris', B. Christian Schmidt ${ }^{2}$ \\ I 5405 Bill Nye Ave., R.R. 3, Laramie, WY 82070, USA. Research Associate: McGuire Center for Lepidoptera \\ and Biodiversity, Florida Museum of Natural History, University of Florida, Gainesville, FL; C. P. Gillette \\ Museum of Arthropod Diversity, Colorado State University, Ft. Collins, CO; Florida State Collection of Arthro- \\ pods, Gainesville, FL 2 Canadian Food Inspection Agency, Canadian National Collection of Insects, Arachnids, \\ and Nematodes, KW Neatby Bldg., 960 Carling Ave., Ottawa, Ontario, Canada K1A OC6 \\ Corresponding authors: Clifford D. Ferris (cdferris@uwyo.edu), Christian Schmidt (Chris.Schmidt@inspection.gc.ca)
}

Academic editor:D. Lafontaine | Received 10 January 2011 | Accepted 10 September 2011 | Published 24 November 2011

Citation: Ferris CD, BC Schmidt (2011) Pterospoda nigrescens (Hulst), a synonym of Ixala klotsi Sperry (Lepidoptera, Geometridae, Ennominae). In: Schmidt, BC, Lafontaine JD (Eds) Contribution to the systematics of New World macromoths III. In: Schmidt BC, Lafontaine JD (Eds) Contributions to the systematics of New World macro-moths III. ZooKeys 149: 31-37. doi: 10.3897/zookeys.149.2343

\begin{abstract}
Comparison of the types of Ixala klotsi (Sperry) and Pterospoda nigrescens (Hulst) shows that they are the same species, with $I$. klotsi a synonym of $P$. nigrescens. A lectotype of Selidosema nigrescens is designated, and the types of $S$. nigrescens and $I$. klotsi are illustrated. Male and female habitus and genitalia of $P$. nigrescens are illustrated.
\end{abstract}

\section{Keywords}

Arizona, Caberini, Ennominae, Geometridae, Ixala, Lepidoptera, Mexico, nomenclature, Pterospoda, taxonomy, Texas

\section{Introduction}

Hulst (1898) described Selidosema nigrescens based on an unknown number of female specimens from San Antonio, Texas. Dyar (1903) subsequently placed Selidosema nigrescens in Pterospoda. Sperry (1940) described Ixala klotsi from two males and a female that he and his wife collected in the Baboquivari Mountains, Pima County, Arizona. We have examined the type material of both taxa and compared contemporary specimens from Texas and Arizona to each other and to the types, 
and conclude that both names refer to the same species. The purpose of this note is to synonymize Ixala klotsi under Selidosema nigrescens, designate a lectotype for the latter, and discuss the generic concepts in the Pterospoda group of genera.

Repository abbreviations:

AMNH American Museum of Natural History, New York, NY, USA

CNC Canadian National Collection of Insects, Arachnids, and Nematodes, Ottawa, Ontario, Canada

CDF Personal collection of Clifford D. Ferris, Laramie, Wyoming, USA

\section{Systematics}

\section{Pterospoda nigrescens (Hulst)}

http://species-id.net/wiki/Pterospoda_nigrescens

Selidosema nigrescens Hulst, 1898:214.

Ixala klotsi Sperry, 1940: 146. syn. n.

Type material. Selidosema nigrescens. Female lectotype [here designated], Texas, [Bexar Co.], San Antonio [AMNH] (Fig. 1). A label for the lectotype will be added as follows: "Lectotype / Selidosema / nigrescens Hulst, 1898 / Ferris \& Schmidt 2011." Ixala klotsi. Male holotype, Arizona, [Pima Co.], Baboquivari Mts. 24 April, 1938, Grace H. and John L. Sperry [CNC] (Fig. 2).

Other material examined. USA. Arizona. Cochise Co.: Forest Road 42B, Coronado Nat. For., 1525m , 19.viii.1981, C. D. Ferris (1m); Guadalupe Canyon, 8.viii.1979, C. D. Ferris (1m); Gray Hawk Nature Preserve, 1235 m, 10.ix.2010, C. D. Ferris (1f). Pima Co.: Baboquivari Mtns., 15. iv [no year], S.E. Cassino (2m); Baboquivari Mts., Brown Canyon, 1183 m, 18.viii.2006, C. D. Ferris (1m), 27.vii.2007, C. D. Ferris (8m, 2f); Baboquivari Mtns., Brown Cyn., 22.iv.2006, B. Walsh (3m); 10.vii.2005 (1m); 2.viii.2008, B. C. Schmidt $(2 \mathrm{~m})$; base of Tortolita Mts., $888 \mathrm{~m}$, all C. D. Ferris, 4-8.iv.2003 (1m, 1f), 27-28.ix.2003 (2m, 2f), 24.x.2003 (1f), 4.x.2004 (1f), 4-11.iv.2005 (1 m, 1f), 24.x.05 (1m), 9.x.2006 (1f). Santa Cruz Co., all C. D. Ferris. Patagonia, 1235 m, 8.viii.2009 (1f); Peña Blanca Canyon, 1200 m, 8.ix.2010 (6m, 1f). Texas. Brewster Co. Green Gulch, Big Bend N. P., 6-10.ix.2008 (1f), B[ordelon]/K[nudson]. Sinton Co., Welder Refuge 4.iv.1981 (1f). Uvalde Co., Concan, Neal's Lodges, 9.iv.1990, N. McFarland (1m, 1f); Concan, 25.iii.1985, E. Knudson (1m). Val Verde Co., Del Rio, 25.iv.1959, M.R. MacKay (1 m, 1f), 4.x.1994 (1m), E. Knudson. MEXICO. Durango: 25 mi. W. of Durango, 7500' 6.v.1961, H. Howden \& J.E.H. Martin (1m); 10 mi. W. of Durango, 7500', 15.v.1964, W.C. McGuffin (1m, 1f); 5 mi. W. of Durango, 6500' 11.vi.964, J.E.H. Martin (1f). 

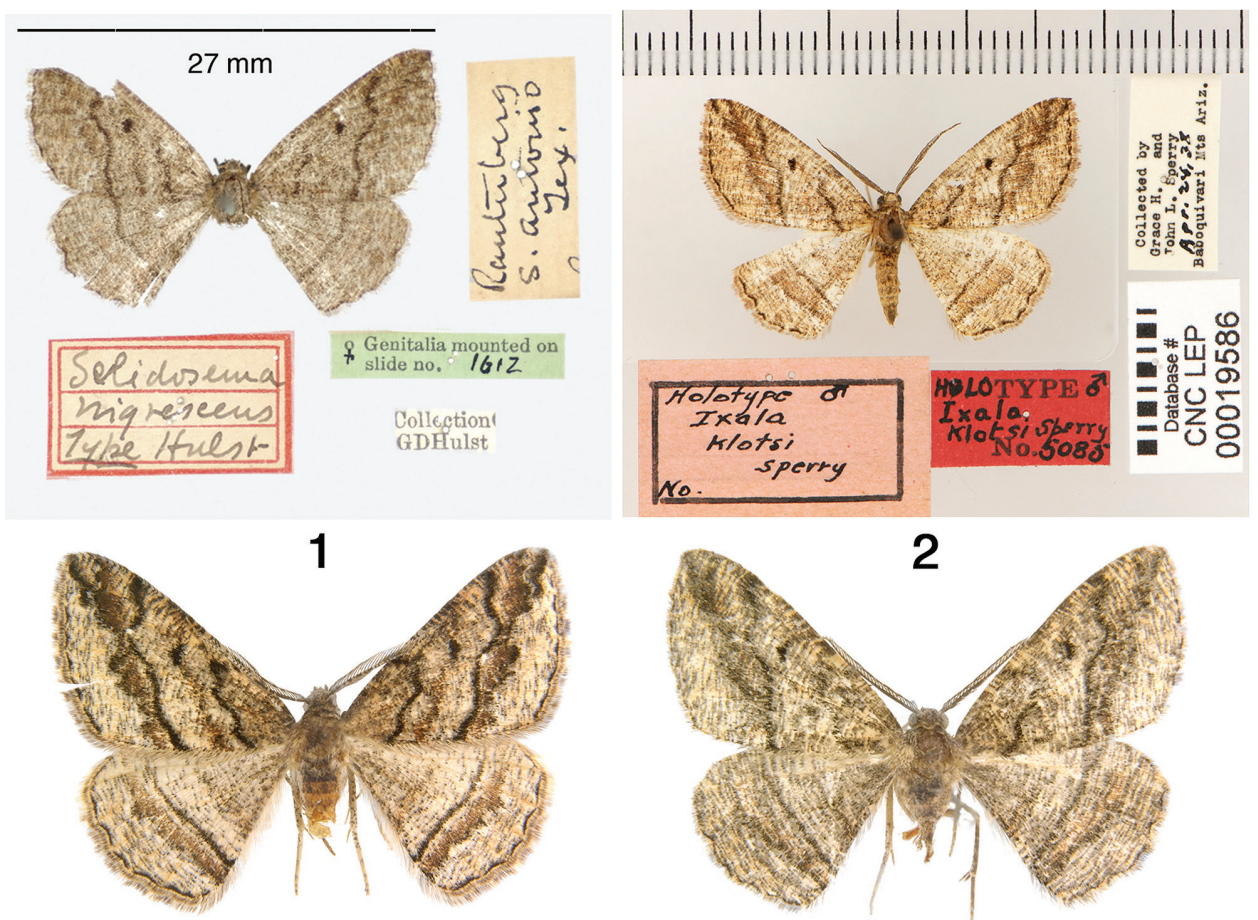

3

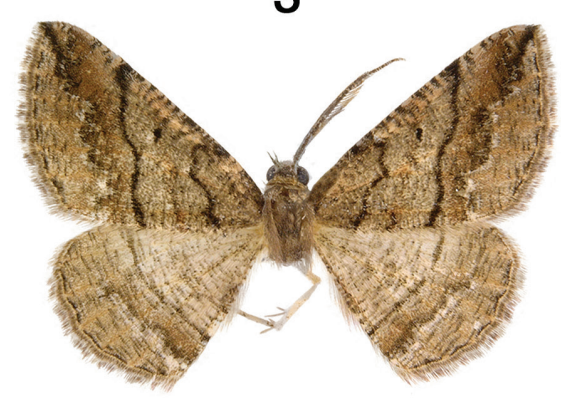

5
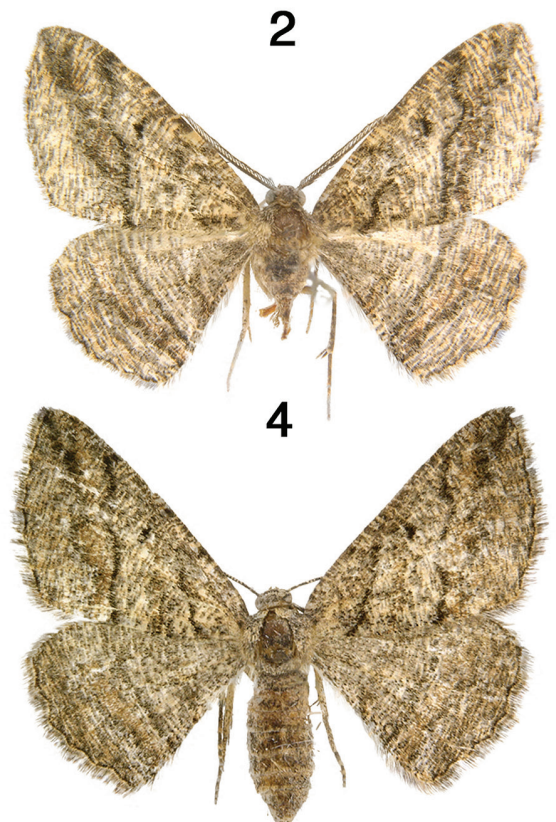

4

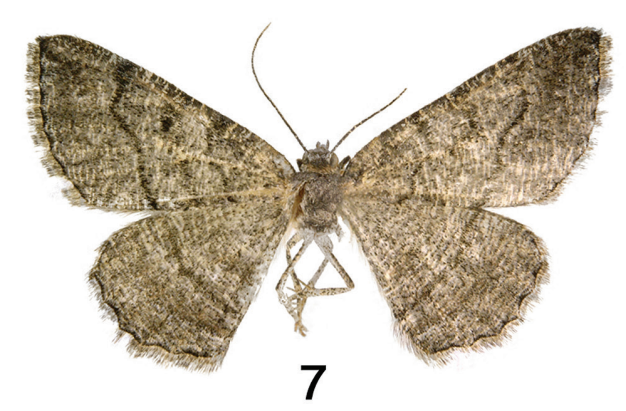

6

Figures I-7. Pterospoda nigrescens. I Lectotype of Pterospoda nigrescens $\mathbf{2}$ Holotype of Ixala klotsi $\mathbf{3}$ male AZ Cochise Co. 4 male AZ Pima Co. $\mathbf{5}$ male TX Val Verde Co. $\mathbf{6}$ female AZ Santa Cruz Co. 7 female TX Brewster Co. 

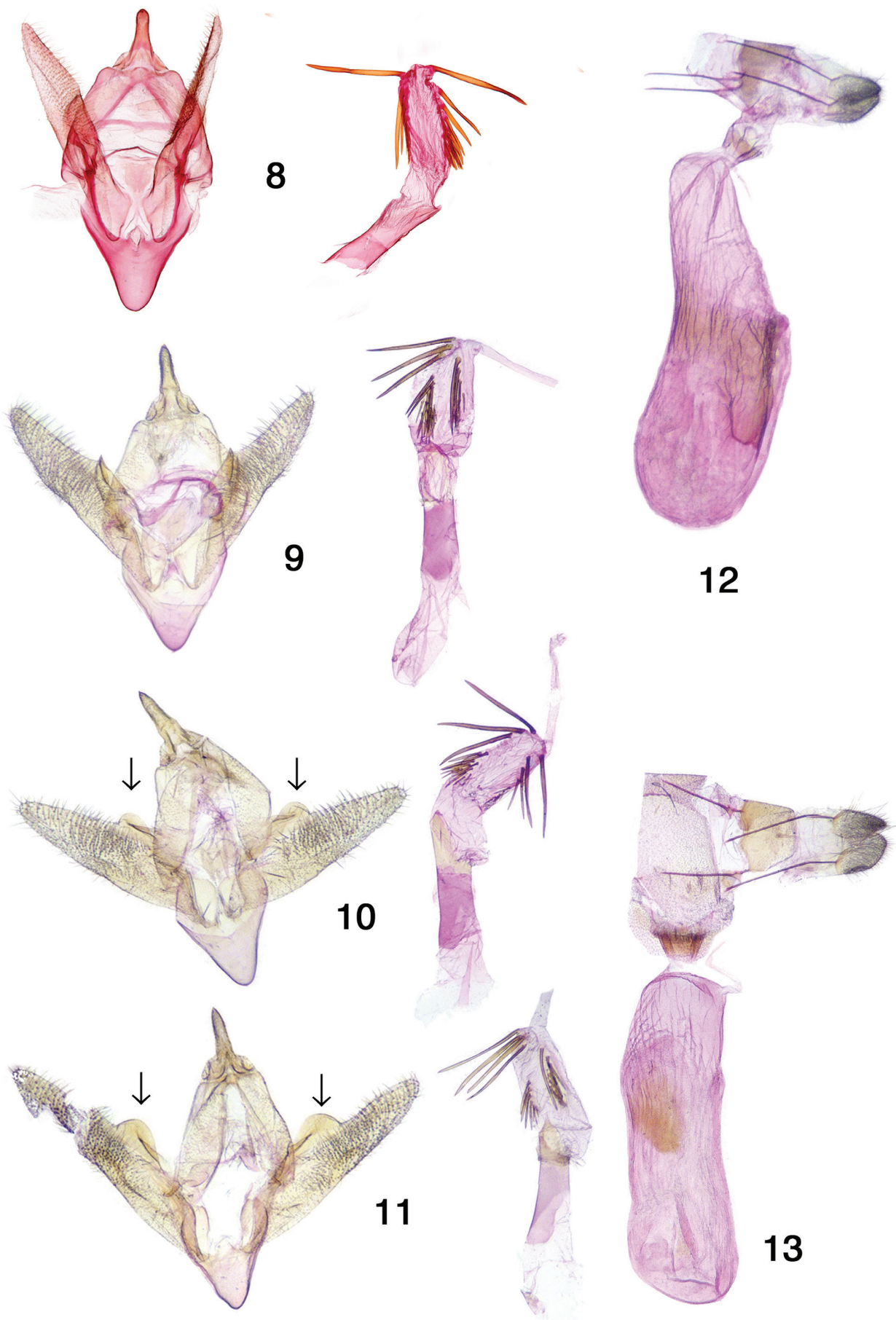

Figures 8-13. Pterospoda nigrescens genitalia. 8 genitalia of $\mathbf{1} 9$ genitalia of $\mathbf{4} \mathbf{1} \mathbf{0}$ male AZ Pima Co. I I genitalia of $\mathbf{5} \mathbf{1} 2$ female AZ Pima Co. 13 genitalia of 7 
Discussion. The type specimen of Selidosema nigrescens in AMNH does not bear a holotype label. Hulst stated in his description: "...all the specimens before me are females." The specimen label data agree with Hulst's description, and we therefore consider this specimen to be a syntype. The locations of the other syntypes are unknown. In order to ensure stability of the name, we designate this specimen as the lectotype (Fig. 1). The holotype of I. klotsi and additional specimens of P. nigrescens are illustrated in Figs 1-7.

Genitalia structure (Figs 8-13). The orientation and degree of flattening of the male genital capsule produces different aspects. The natural position is shown for the holotype of Ixala klotsi (Fig. 8). A partially flattened preparation is shown in Fig. 9, and strongly flattened preparations in Figs 10-11, in which the approximately semicircular projections (indicated by arrows) at the base of the costa become evident. The number and positions of the spines on the everted vesicae are somewhat variable, suggesting that the spines are partially deciduous. The balsam genitalia slide of the female lectotype of Pterospoda nigrescens was made in 1950 without use of stains, and the tissues were strongly cleared. There is very little contrast between the preparation and the now yellowed balsam, and we were unable to obtain a photograph suitable for publication. The form of the genitalia is consistent with specimens from Texas (Fig. 13) and Arizona (Fig. 12). The corpus bursae of the Texas specimen (Fig.13) appears slightly smaller than that of the Arizona specimen (Fig. 12). Upon dissection, it was found to be only partially expanded, and was mechanically manipulated into the position shown.

Ixala Hulst and Pterospoda Dyar were placed in the Caberini along with 11 other genera by Ferguson (1983), the most recent tribal classification for this primarily North American tribe. Only Pterospoda and Sericosema Warren enter the Neotropical region in Mexico (Pitkin 2002). Rindge (1949) revised the Drepanulatrix group of genera, but the remaining genera in Caberini are in need of revision. For example, preliminary data suggest that both Ixala and Pterospoda as currently defined are not natural groups; Pterospoda opuscularia (Hulst), the type-species of Pterospoda, is more closely related to Apodrepanulatrix litaria (Hulst), and the remaining species in Ixala and Pterospoda have little in common in both facies and genitalic structure.

Pterospoda nigrescens occurs at moderate elevations in arid scrub and open woodland habitat, ranging from south-eastern Arizona and the Edwards Plateau of west-central Texas south to at least Durango, Mexico (Fig. 14). It is not known from New Mexico, but should occur there. Collection dates indicate at least two annual flights, primarily in April and August in Arizona. In Pima Co., AZ, Ray Nagle (Tucson, AZ) has reared the moth on a Condalia species, probably C. warnockii var. kearneyana M. C. Johnson (Rhamnaceae). 


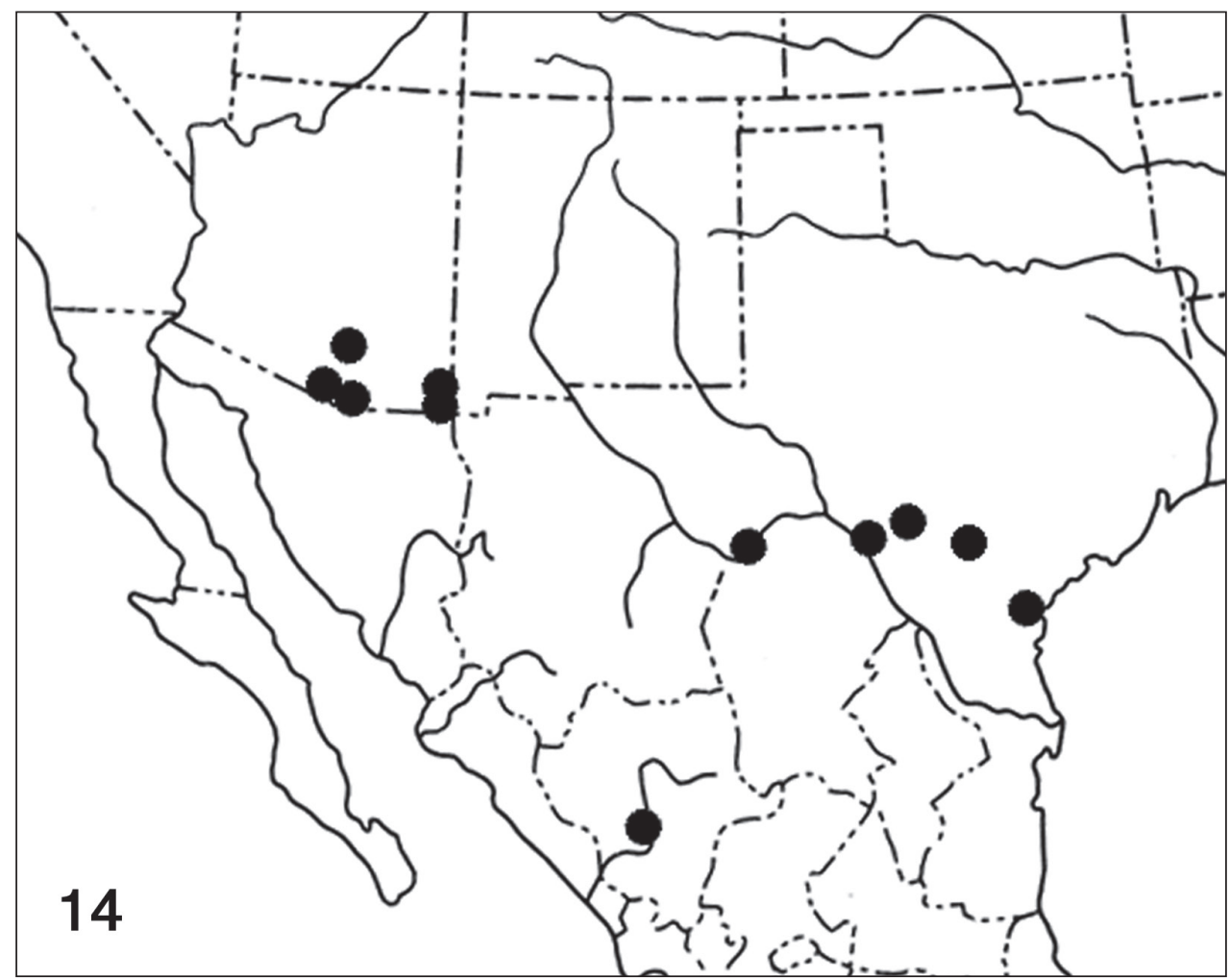

Figure 14. Distribution map for Pterospoda nigrescens.

\section{Acknowledgments}

We thank Suzanne Rab Green (AMNH) for photographs and loan of the genitalia slide of Pterospoda nigrescens, and Jocelyn Gill (CNC) for technical support. Bruce Walsh (Tucson, AZ) kindly provided additional specimens and Ed Knudson (Houston, TX) made available Texas material for study. As external reviewers, G. G. Anweiler, Edmonton, AB, and J. B. Sullivan, Beaufort, NC provided helpful suggestions.

\section{References}

Dyar HG (1902 [1903]) A list of North American Lepidoptera and key to the literature of this order of insects. Bulletin of the United States National Museum 53: 1-xixx + 723 pp. Ferguson DC (1983) Geometridae. In: Hodges RW, Dominick T, Davis DR, Ferguson DC, Franclemont JG, Munroe EG, Powell JA (Eds) Check list of the Lepidoptera of America north of Mexico. E.W. Classey Ltd. and Wedge Entomological Research Foundation,London, $88-107$. 
Hulst GD (1898) Descriptions of new genera and species of the geometrina of North America. Canadian Entomologist 30: 214-219. doi: 10.4039/Ent30214-8

Pitkin LM (2002) Neotropical ennomine moths: a review of the genera (Lepidoptera: Geometridae). Zoological Journal of the Linnean Society 135: 121-401. doi: 10.1046/j.10963642.2002.01200.x

Rindge FH (1949) A revision of the geometrid moths formerly assigned to Drepanulatrix (Lepidoptera). Bulletin of the American Museum of Natural History 94: 231-298.

Sperry JL (1940) Two apparently undescribed species of Geometridae from the Southwest. Canadian Entomologist 72: 145-147. doi: 10.4039/Ent72145-7 